\title{
De onde vem o seu queijo? O cenário da comercialização do queijo tipo colonial em feiras do município de Santa Maria, RS, Brasil
}

Valéria Pinheiro Braccini, Regis Trentin Piovesan, Janaina Balk Brandão, Neila Silvia

Pereira dos Santos Richards

https://doi.org/10.4322/mp.978-65-991393-2-1.c1

\section{Resumo}

A produção artesanal de queijos na região central do Rio Grande do Sul é uma herança da colonização e perpetua-se ao longo do tempo. Além de servir como alimento para as famílias, o excedente de queijo colonial é comercializado pelos agricultores como complemento de renda. Dessa forma, objetivou-se identificar os tipos de feirantes existentes bem como compreender a origem dos queijos comercializados em feiras do município de Santa Maria/RS, Brasil. Para cumprir com os objetivos, fez-se uma revisão conceitual acerca das cadeias produtivas, das feiras e do queijo colonial. Através dos dados levantados pelo Grupo Interdisciplinar de Pesquisas Agroalimentares - GIPAG junto às feiras do município foi realizado um recorte dos dados de produção de queijo colonial, dividindo os feirantes de acordo com a origem do produto comercializado por eles, sendo: a) "Feirantes que comercializam queijos oriundos de produção própria", b) "Feirante com venda de queijo oriundo de produção mista" e c) "Feirantes que revendem queijos produzidos por outros produtores" Após essa divisão, através de três entrevistas com informantes qualificados, identificou-se as diferenças na cadeia produtiva de cada um desses grupos de feirantes. Conforme o resultado da pesquisa foram identificados três canais de comercialização pelos quais os feirantes adquirem o queijo informal em Santa Maria/RS, Brasil, sendo eles empresas que são fiscalizadas por órgãos oficias estaduais, empresas que são fiscalizadas pelo órgão de vigilância municipal e empresas que não passam por nenhum tipo de fiscalização. As conclusões do trabalho dão conta de que as questões acerca da legalização da produção e estratégias de comercialização do queijo colonial são importantes do ponto de vista de saúde pública, no entanto, é necessário atender as demandas e as particularidades que os agricultores familiares têm em relação a um modo de produção historicamente constituído. Deste modo, o desafio é encontrar um meio termo em que não se perca o que foi constituído, preservando o histórico cultural da região, ao mesmo tempo em que as condições sanitárias adequadas sejam respeitadas.

Palavras-chave: Canais de comercialização; produção artesanal; saúde pública.

\section{Introdução}

A produção artesanal de queijos é uma herança cultural da colonização ocorrida na Região Central do Rio Grande do Sul e o saber-fazer vem sendo transmitido pelas famílias ao longo das gerações [1]. O queijo colonial produzido no sul do Brasil, além de ser utilizado como alimento para as famílias dos produtores rurais, passou a ser importante fonte de renda quando teve seu excedente comercializado [2]. Segundo 
Costa et al. [3] a importância do setor de leite e derivados, dentre eles o queijo, é representada quando para cada $\mathrm{R} \$ 1$ milhão em produtos demandados do leite, 197 empregos são geridos, corroborando com os dados fornecidos pela Empresa Brasileira de Pesquisa Agropecuária - EMBRAPA [4], que elege o leite como um dos seis produtos agropecuários de importância, tanto como elemento básico da alimentação quanto fonte de emprego e renda para a população brasileira.

No Brasil, uma das cadeias produtivas mais relevantes para agronegócio é a do leite [5]. A cadeia produtiva do leite pode ser representada por diversos segmentos a exemplo dos fornecedores, os quais providenciam insumos, máquinas e equipamentos aos produtores; dos produtores rurais, que podem ser especializados ou não; pela indústria, que coleta o produto junto aos produtores e os distribui e por fim, pelo sistema agroindustrial, como varejistas, supermercados e padarias [6].

A importância da cadeia é representada pelo aumento da demanda mundial da produção leiteira. A International Farm Comparision Network [7] publicou o Relatório Anual que traduz a expectativa de que a produção de leite aumente em 304 milhões de toneladas por ano para suprir a necessidade mundial em 2030. O Anuário do Leite [8] evidencia o potencial brasileiro no cenário setor lácteo. O Brasil é o quinto maior produtor de leite, ficando atrás da Índia, Estados Unidos, Paquistão e China. No entanto, o País encontra-se em estagnação desde 2015 [9] reflexo da crise econômica, quando ocorreram quedas de $2,8 \%$ e $3,7 \%$ na produção leiteira, corroborando com os dados da EMBRAPA [8] que confirmam que a produção de leite inspecionada foi 24,7 bilhões de litros e volume total produzido de 35,1 bilhões de litros.

Sabe-se que a cadeia produtiva de queijo colonial é composta por diversos elos como a indústria de insumos, produção, distribuição, comercialização e consumo. Assim, a cadeia produtiva é definida como uma sucessão de transformação dissociáveis, capazes de ser separadas e ligadas, entre si por um encadeamento técnico. É um arranjo composto por diversas esferas econômicas que relacionadas em sequência no processo, agregam valor ao produto a cada atividade produtiva e de comercialização [10].

É neste contexto que Zylbersztajn [11] define que a troca de bens e serviços entre os agentes econômicos, é compreendida como comercialização. Dessa forma, quando os bens fluem pelos canais de comercialização e de distribuição, quanto mais elaborada for a combinação envolvida, maior é a coordenação entre os componentes do sistema e quanto mais direta for, menores serão os custos de transação associados.

A definição para os canais de comercialização já havia sido caracterizada por Kotler [12] conforme o seu comprimento e número de intermediários que compõem o processo. Para o autor, podem ser encontrados: "canal de nível zero", onde o produtor comercializa diretamente com o consumidor final, "canal de um nível" em que há um intermediário envolvido, "canal de dois níveis", composto por dois intermediários na comercialização dos produtos agrícolas; "canal de três níveis" representado por três intermediários na negociação e "canal de quatro níveis" composto por quatro agentes. Enquanto os canais longos formados por indústrias de abastecimento convencional, distanciam os atores entre si, as cadeias curtas de produção e comercialização surgem como alternativa reduzindo a distância física de extensão e percurso entre os produtores e os consumidores finais dos alimentos [13].

A produção e a comercialização de queijos tipo colonial sem inspeção sanitária são consideradas ilegais no Brasil [14], motivando ações fiscalizadoras e apreensões de produtos em feiras e mercados da região central do Rio Grande do Sul $[15,16]$. No 
entanto as irregularidades às especificações sanitárias não estão restritas a pequenos mercados ou feiras de agricultura familiar. Mandados de busca e apreensão em estabelecimentos regulares resultaram na retirada de aproximadamente nove toneladas de alimentos impróprios para o consumo, interdições e suspensões das atividades comerciais [17], gerando descrédito nas instituições estabelecidas.

Os debates relacionados ao comércio de queijo colonial são motivados pelo cumprimento das normas da legislação brasileira, que prevê na produção o uso de leite pasteurizado, tempo de cura inferior a 30 dias, informações de rotulagem com data de fabricação, prazo de validade e inspeção sanitária $[18,19]$. Tais exigências são incompatíveis com a pequena produção e nessas circunstâncias, os agricultores familiares inserem-se no mercado informal [20].

A análise da cadeia produtiva do queijo colonial em feiras de Santa Maria/RS, Brasil, tendo como elo focal os feirantes, proporciona estabelecer quais os agentes envolvidos na produção e comercialização do produto bem como compreender as estratégias utilizadas pelos feirantes na aquisição do produto. Dessa forma, objetivouse verificar os diferentes tipos de feirantes existentes para compreender a origem do produto e assim, quantificar a comercialização de queijo colonial em feiras do município.

Frente à diversidade de componentes envolvidos no processo de produção e comercialização de queijo tipo colonial e as apreensões recorrentes em ações fiscalizadoras de vigilância sanitária, o estudo justifica-se pela necessidade de investigar os diferentes tipos de feirantes e identificar a origem do produto ofertado nas principais feiras de Santa Maria/RS, Brasil.

\subsection{Caracterização do Queijo Colonial}

Produtos coloniais são aqueles produzidos artesanalmente na propriedade dos "colonos", os quais realizam a produção para seu consumo e comercializam o excedente [21]. No sul do Brasil, é utilizada a denominação "colonial" aos alimentos preparados por descendentes de europeus, principalmente aqueles de língua italiana e alemã, cujas terras recebidas no século XIX eram denominadas de "colônia" [1, 22]. Para Xavier e Brito [23] um produto colonial pode ser assim definido desde que considere a origem geográfica da produção, a matéria-prima bem como o processo artesanal envolvido e os saberes preservados pelas gerações e aplicados na fabricação do alimento.

O queijo colonial é o produto obtido por meio da coagulação do leite bovino, coalho e/ou outras enzimas coagulantes, podendo ser consumido fresco ou em diversos graus de maturação. As suas características físicas mais comuns são o formato arredondado e peso aproximado de um quilograma, podendo ou não apresentar casca quando imaturo, superfície fina e amarelada quando maduro ou dura e mais espessa quando submetido à maturação mais longa [24].

Conforme a Portaria do Ministério da Agricultura, Pecuária e Abastecimento (MAPA) de no 146, de 07/03/1996, a denominação de queijo está reservada aos produtos com base láctea que apresente apenas gordura e/ou proteínas de origem láctea em sua composição [18]. A Portaria SEAPPA no 55 de 28/03/2014, fixou o Normas Técnicas de Instalações e Equipamentos para Microqueijarias, denominando como queijo artesanal, produtos fabricados em pequena escala a partir do leite obtido de animais sadios, beneficiado no estabelecimento de origem, de acordo com os processos tradicionais que Ihe confira consistência, coloração e sabor próprios, seguindo Regulamentos Técnicos de Identidade e Qualidade específicos-RTIQ. 
A produção de queijo colonial a partir de matéria-prima crua, não corresponde aos padrões de qualidade e identidade proposta pela legislação sanitária. Distintos fatores como origem do leite, raça do animal, tipo de pastagem, período de lactação, condições de maturação, por exemplo, influenciam no processo de fabricação de queijos de boa qualidade, proporcionando sabor e aroma diferenciados [25, 26, 27]. Dessa forma, a produção rural de queijo artesanal tem participação econômica importante devido à expressiva importância na formação de renda dos produtores de leite, principalmente daqueles que comercializam o excedente da sua produção [28]. Em recente pesquisa, Mattielo et al. [22] ressaltaram que o queijo colonial ainda não possui um RTIQ e alerta para a importância de que sejam fixados valores de referência para análise da composição e padronização desse tipo de queijo.

Referente ao que é preconizado pela legislação brasileira, a fundamentação em modelos tecnicistas não contempla as realidades locais, generalizando as exigências sanitárias e limitando a oferta de produtos frescos oriundos da agricultura familiar aos mercados informais. Colleti [29] corrobora com o pensamento de que apesar da informalidade, a institucionalidade própria dos mercados informais regula as relações pessoais, permitindo aos consumidores reconhecer e valorizar o produtor pela qualidade oferecida, tornando assim, o produto socialmente controlado.

\subsection{Cadeia Produtiva De Queijo Colonial}

Para Batalha [10] a cadeia produtiva é composta por diversos elos como a indústria de insumos, produção, distribuição, comercialização e consumo. Dentre as formas pelas quais se caracteriza a produção e distribuição de queijos, encontra-se a produção artesanal comercializada de forma direta ao consumidor. De acordo com o autor, a cadeia produtiva é uma sucessão de transformação dissociáveis, capazes de ser separadas e ligadas entre si por um encadeamento técnico. É um arranjo composto por diversas esferas econômicas que relacionadas em sequência no processo, agregam valor ao produto a cada atividade produtiva e de comercialização.

Para Canzoani [6] a cadeia produtiva do leite pode ser representada por diversos segmentos a exemplo dos fornecedores, os quais providenciam insumos, máquinas e equipamentos aos produtores; dos produtores rurais, que podem ser especializados ou não; pela indústria, que coleta o produto junto aos produtores e os distribui e por fim, pelo sistema agroindustrial, como varejistas, supermercados e padarias. Os diferentes elos relacionam desde o produtor de insumos para a produção de leite até o consumidor final, necessitando de coordenação ao longo do processo [30]. Desta forma, como uma cadeia produtiva não pode ser limitada à uma determinada região e por ser amplamente interativa pela distribuição de produtos que extrapolam os limites geográficos, por vezes é considerada como um fator gerador de riscos, e agravos à saúde e ao meio ambiente [31].

Devido aos avanços tecnológicos a agricultura passou a depender de muitos serviços, máquinas e insumos externos às propriedades, além de armazéns, infraestruturas, agroindústrias, mercados atacadista e varejista e exportação [32]. Assim, para compreender a nova realidade da agricultura, os autores Davis e Goldberg [33] criaram o termo agribusiness e o definiram como sendo a soma de todas as operações e transações envolvidas desde a fabricação dos insumos agropecuários, das operações de produção nas unidades agropecuárias, até o processamento e distribuição e consumo dos produtos agropecuários in natura ou industrializados.

Posteriormente na década de 1960, na Escola Francesa de Organização Industrial na França o termo filière foi conceituado como sendo uma sequência de operações que 
conduzem à produção de bens, cuja articulação é amplamente influenciada pelas possibilidades tecnológicas e definida pelas estratégias dos agentes.

Assim, a partir da noção de filière torna-se possível compreender as relações estabelecidas entre os agentes econômicos durante o processo produtivo. A descrição da estrutura e o funcionamento de uma atividade econômica, considerando os caminhos percorridos para a elaboração de um produto final, as estratégias escolhidas pelos agentes para obter as condições favoráveis nas relações de força que mantêm com fornecedores, clientes e concorrentes mantendo-se competitivo, aumentando a rentabilidade [34].

Os conceitos de cadeias produtivas estão em constantes adaptações. O conceito elaborado por Zylbersztajn [35] define cadeias produtivas como operações organizadas de forma vertical a qual o produto percorre desde a produção até a distribuição e são coordenadas através do mercado ou da intervenção dos agentes que participam da cadeia. Para Batalha [10] cadeia produtiva pode ser compreendida como a soma de todas as etapas de produção e comercialização necessárias para transformar matérias primas em um determinado produto final, ou seja, até que o mesmo chegue ao consumidor final. As constantes mudanças nas estruturas organizacionais fizeram com que as cadeias produtivas se tornassem mais complexas, evidenciando a necessidade da inclusão dos atores sociais e suas interações para que as relações ao longo da cadeia sejam compreendidas [36].

As cadeias curtas caracterizadas pelo encolhimento nos processos de elaboração e negociações a exemplo do queijo colonial comercializado em feiras despertam o interesse por pesquisas microbiológicas que indicam a informalidade e ausência de inspeção como um risco potencial à saúde pública. Fava et al. [37] ao analisarem queijos artesanais comercializados em uma feira agropecuária do Rio Grande do Sul, encontraram irregularidades como a ausência de informações referentes à pasteurização do leite, quantidade de ingredientes obrigatórios como coalho e sal e carimbo de inspeção sanitária, conforme previstas no Regulamento da Inspeção Industrial e Sanitária de Produtos de Origem Animal - RIISPOA [14].

Ide e Benedet [2] ao analisarem amostras de Queijo Serrano produzidos em Santa Catarina encontraram resultados variados sobre composição, forma e peso do produto e presença de contaminação por coliformes fecais decorrentes da ausência de padronização das técnicas de fabricação e das condições higiênica sanitária insuficiente [38]. Zaffari et al. [39] após monitorarem a qualidade bacteriológica de queijos artesanais comercializados em estradas do litoral norte do Rio Grande do Sul, concluíram que a maioria dos produtos testados apresentavam contagens de coliformes fecais acima dos valores considerados inócuos. Tais resultados corroboram com os resultados encontrados por Santos-Koelln et al. [40] no Paraná quando as amostras em estudo revelaram contaminações acima dos limites aceitáveis pela legislação vigente.

\subsection{Feiras}

As feiras coloniais, além de ser um caminho de fortalecimento da cultura regional, uma vez que os produtores carregam consigo suas tradições, saberes e modos de cultivar seus produtos, representam os canais de comercialização dos produtos provenientes da agricultura familiar [1]. Assim, tornam-se uma forma organizada de inserção dos produtores no mercado para a distribuição de produtos artesanais e de qualidade [13].

A comercialização direta é a alternativa utilizada pela agricultura familiar, apesar das convenções industrial-mercantis predominarem [41]. Apesar disso, as feiras tornaram- 
se espaços emblemáticos de cadeias curtas e as práticas como a diversificação, o autoconsumo e a comercialização entre produtor e consumidor garantem geração de renda e segurança alimentar e nutricional para os que se abastecem diretamente nesses espaços [42]. A virada da qualidade é o que motiva o movimento que contrapõe o modelo de produção e consumo em massa associado a globalização e as cadeias agroalimentares longas [43].

Entretanto, para a legislação brasileira o conceito de qualidade dos alimentos está relacionado à capacidade de produção e às ferramentas envolvidas no processo produtivo [44]. Segundo os autores supracitados, há incentivo para o desenvolvimento industrial, aqui representado pelas estruturas que conseguem preencher as exigências estabelecidas pelo padrão de inocuidade, conforme requer a legislação sanitária e, dessa forma, marginalizam os agricultores familiares que não conseguem cumprir as normas sanitárias instituídas.

A crise dos sistemas alimentares modernos tem origem econômica e as superestruturas não são consideradas sinônimos de qualidade [44]. Os recentes escândalos envolvendo a indústria alimentar $[45,46]$ contribuíram para que as feiras sejam associadas às mudanças sociais referentes ao padrão alimentar. O fenômeno da virada da qualidade dos alimentos está relacionado aos recentes riscos alimentares, críticas e descontentamento ao atual modelo de produção, processamento e distribuição dos alimentos [43]. A produção de alimentos artesanais, por sua vez, ocorre em escalas de processamento menores, a comercialização dos produtos ocorre em sistemas locais e as relações de confiança entre produtores e consumidores são usadas para legitimar a qualidade desses produtos. No entanto, a legislação sanitária adota padrões hegemônicos para a produção de alimentos em grande escala e não facilita o acesso de pequenos produtores às práticas e condutas de inocuidade previstas, dificultando assim, a inserção dos mesmos no mercado [13].

\section{Material e Métodos}

O presente artigo é um estudo descritivo, exploratório e de abordagem qualitativa, pois procura quantificar e entender, a partir de dados e reflexões pontuais, os agentes envolvidos diretamente nessa atividade. Desta forma, buscou-se identificar as particularidades apresentadas pelos feirantes que compõem o elo focal da cadeia, com o intuito de compreender a origem do queijo colonial comercializado.

Segundo Guerra e Teodósio [47] em uma abordagem qualitativa, o objetivo é a profundidade e a compreensão dos fenômenos como, por exemplo, as ações dos indivíduos, grupos ou organizações in loco ou contexto social, sem que a representatividade numérica seja de suma importância. A pesquisa também possui um caráter exploratório, pois não há estudos sobre o tema na Região Central do Rio Grande do Sul. Para Gil [48] pesquisas descritivas proporcionam, por vezes, uma nova visão do problema, aproximando-se de pesquisas caracterizadas como exploratórias.

O primeiro passo da pesquisa foi realizar uma revisão bibliográfica acerca das feiras de comercialização de produtos coloniais, sobre o que significa queijo colonial, além da temática das cadeias produtivas, que é o ponto de análise que o artigo objetiva. Após isso, buscou-se junto aos dados do Grupo Interdisciplinar de Pesquisas Agroalimentares - GIPAG - da UFSM os dados relacionados ao queijo colonial em feiras do município de Santa Maria/RS, por meio de um documento de acesso exclusivo em meio eletrônico [49]. O GIPAG vem desenvolvendo um levantamento de dados acerca da produção e comercialização em feiras do município desde o ano de 2017 e os resultados estão sistematizados pelo grupo em um banco de dados próprio. Assim, foi realizado um recorte visando classificar e quantificar os feirantes e a 
produção relacionada somente ao queijo colonial.

Por meio dos dados fornecidos pelo GIPAG, os feirantes que comercializam queijo colonial no município foram categorizados em três grandes grupos, de acordo com a origem do queijo comercializado, denominados "Feirantes que comercializam queijos oriundos de produção própria", "Feirantes que revendem queijos produzidos por outros produtores" e "Feirante com venda de queijo oriundo de produção mista". Após essa divisão, procurou-se identificar as diferenças na cadeia produtiva de cada um desses grupos de feirantes. Para isso, realizaram-se três entrevistas com informantes qualificados nas feiras, sendo um informante que tem sua produção registrada e inspecionada pelo Serviço Municipal de Inspeção, um informante, cuja produção não é legalizada e um informante que tem sua produção registrada e inspecionada em outro município da região, buscando identificar: a) os aspectos históricos da produção e comercialização de queijo; b) os canais de compra de suprimentos e insumos para produção; c) os canais de comercialização utilizados, além da feira, e d) a origem da opção pela comercialização de seus produtos em feiras.

\section{Resultados e Discussões}

\subsection{Grupos de Feirantes}

Primeiramente, os feirantes foram agrupados de acordo com a origem do queijo colonial que comercializam. No primeiro grupo foram categorizados os feirantes que produzem e comercializam queijo colonial formalmente, aqui representados por produtos relacionados à economia formal, legalmente estabelecidos, registrados e com impostos recolhidos. No segundo grupo, foram incluídos feirantes que comercializam queijo colonial de produtores formalizados advindos de outros municípios e o revende e no terceiro grupo, foram categorizados os feirantes que tanto comercializam os queijos que produzem informalmente quanto os queijos adquiridos em agroindústrias formalizadas. A Tabela 1 apresenta os dados gerais coletados referente a comercialização de queijo colonial nas principais feiras do município de Santa Maria/RS.

Observa-se pelos dados da Tabela 1 que o município de Santa Maria/RS conta com dez feiras que comercializam queijo colonial, onde encontram-se quatro feirantes que produzem e comercializam queijos provenientes de suas propriedades, vinte e três feirantes que revendem queijos produzido em agroindústrias e um feirante que comercializa queijos derivados parte de produção artesanal e parte adquiridos em agroindústrias, perfazendo a venda anual de $46.760 .00 \mathrm{~kg}$ do produto no município.

Durante a entrevista, foram identificados feirantes que adotam práticas de comercialização distintas nas feiras do município, no que se refere a origem do queijo: "Feirantes que comercializam queijos oriundos de produção própria", "Feirantes que revendem queijos produzidos por outros produtores" e "Feirante com venda de queijo oriundo de produção mista".

Entende-se por "Feirantes com produção própria", os produtores de queijo que realizam a produção no seu estabelecimento e comercializam nas feiras locais, de forma legalizada ou não. No total, nas principais feiras do município são comercializados aproximadamente $18.080 \mathrm{~kg} / \mathrm{ano}$ de queijo tipo colonial oriundos de produção própria. Estes números indicam que, apesar de somente um feirante ser legalizado e ter seus produtos inspecionados pelo Serviço de Inspeção Municipal de Santa Maria/RS, queijos tipo colonial, produzidos de forma artesanal estão sendo normalmente comercializados no município [49]. 


\begin{tabular}{|c|c|c|c|c|c|c|c|c|}
\hline \multirow[b]{2}{*}{ Feira } & \multicolumn{2}{|c|}{ Produção Própria } & \multicolumn{2}{|c|}{$\begin{array}{c}\text { Produção } \\
\text { Terceirizada }\end{array}$} & \multicolumn{2}{|c|}{ Produção Mista } & \multicolumn{2}{|c|}{ Total } \\
\hline & $\begin{array}{l}\text { Número } \\
\text { produtores }\end{array}$ & $\begin{array}{c}\mathrm{Kg} \\
\text { vendidos/ } \\
\text { ano }\end{array}$ & $\begin{array}{l}\text { Número } \\
\text { produtores }\end{array}$ & $\begin{array}{c}\mathrm{Kg} \\
\text { vendidos/ } \\
\text { ano }\end{array}$ & $\begin{array}{l}\text { Número } \\
\text { produtores }\end{array}$ & $\begin{array}{c}\mathrm{Kg} \\
\text { vendidos/ } \\
\text { ano }\end{array}$ & $\begin{array}{l}\text { Número } \\
\text { produtores }\end{array}$ & $\begin{array}{c}\mathrm{Kg} \\
\text { vendidos/ } \\
\text { ano }\end{array}$ \\
\hline $\begin{array}{l}\text { Roraima } \\
\text { Feirão }\end{array}$ & 1 & 400 & 3 & 2.080 & 1 & 2.500 & 5 & 4.980 \\
\hline $\begin{array}{l}\text { Colonial } \\
\text { Saldanha }\end{array}$ & 12 & 9290 & 2 & 1000 & 0 & 0 & 3 & 10290 \\
\hline $\begin{array}{l}\text { Marinho } \\
\text { Roque }\end{array}$ & 0 & 0 & 0 & 0 & 0 & 0 & 0 & 0 \\
\hline Gozales & 0 & 0 & 0 & 0 & 0 & 0 & 0 & 0 \\
\hline T.N. & 1 & 400 & 0 & 0 & 0 & 0 & 1 & 400 \\
\hline $\begin{array}{l}\text { Polifeira } \\
\text { Professor }\end{array}$ & 1 & 8.640 & 0 & 0 & 0 & 0 & 1 & 8.640 \\
\hline $\begin{array}{l}\text { Teixeira } \\
\text { Vale }\end{array}$ & 0 & 0 & 6 & 6.260 & 0 & 0 & 6 & 6.260 \\
\hline $\begin{array}{l}\text { Machado } \\
13 \text { de }\end{array}$ & 0 & 0 & 3 & 2.380 & 0 & 0 & 3 & 2.380 \\
\hline $\begin{array}{l}\text { maio } \\
\text { Saturnino }\end{array}$ & 0 & 0 & 4 & 2.760 & 0 & 0 & 4 & 2.760 \\
\hline de Brito & 0 & 0 & 3 & 6.100 & 0 & 0 & 3 & 6.100 \\
\hline $\begin{array}{l}24 \text { horas } \\
\text { Morada }\end{array}$ & 0 & 0 & 1 & 1.500 & 0 & 0 & 1 & 1.500 \\
\hline Nova & 0 & 0 & 1 & 1.000 & 0 & 0 & 1 & 1.000 \\
\hline Total & 15 & 18.730 & 23 & 22180 & 1 & 2.500 & 28 & 43410 \\
\hline
\end{tabular}

Fonte: Adaptado de [49].

Tabela 1. Número de feirantes, quantidade vendida por grupo de feirantes e feiras do município de Santa Maria/RS, Brasil.

$\mathrm{Na}$ categoria identificada como "feirantes que revendem queijos produzidos por outros produtores", foram incluídos os feirantes que adquirem e comercializam queijos de outros produtores estabelecidos em municípios próximos, com inspeção municipal ou estadual. No total, nas principais feiras do Município há vinte e três feirantes [49] que comercializam aproximadamente $26.180 \mathrm{~kg} / \mathrm{ano}$ de queijo provenientes de produtores de outros municípios, com selo de inspeção municipal ou estadual.

Foi incluído na categoria de "feirante com venda de queijos oriundo de produção mista", o feirante que trabalha com queijos oriundos de sua produção quanto adquire de outro produtor. Tanto a prática de comercializar queijo oriundo de produção mista, quanto a de revender queijos produzidos em outro munícipio somente com inspeção municipal, não está em conformidade com a Lei 7.889/1989 - que dispõe sobre a Inspeção Sanitária e Industrial dos Produtos de Origem Animal e define que os municípios possuem competência para fiscalização de estabelecimentos apenas no comércio municipal. Segundo a Confederação Nacional de Municípios [50], os produtos locais que circulam e são comercializados em outros municípios, devem obrigatoriamente possuir o selo de fiscalização conforme as exigências de certificação do Sistema Unificado de Atenção à Sanidade Agropecuária -SUASA.

\subsection{Estratégias de Comercialização dos Diferentes Grupos de Feirantes}

Os feirantes que comercializam queijo colonial no município que foram agrupados de acordo com a origem do queijo comercializado, denominados por "Feirantes que comercializam queijos oriundos de produção própria", "Feirantes que revendem queijos produzidos por outros produtores" e "Feirante com venda de queijos oriundos de produção mista" apresentam diferenças em sua cadeia produtiva. As entrevistas com os informantes qualificados nas feiras do município possibilitaram a compreensão 
sobre os aspectos históricos da produção e comercialização de queijo, quanto aos canais de compra de suprimentos e insumos para produção, quanto aos canais de comercialização utilizados, além da feira e quanto à sua opção pela comercialização de seus produtos em feiras.

Dessa forma, o feirante com produção própria, por ter uma produção em maior escala do que os demais produtores, efetua a compra de leite de um fornecedor, elaborando todos os processos de produção, armazenamento, embalagem e rotulagem. Por ser uma agroindústria legalizada e inspecionada por órgãos fiscalizadores locais, tem a possiblidade de comercializar seus produtos em mercados e padarias do município. No entanto, o principal canal de comercialização escolhido são as feiras locais, que por ser um local de venda direta ao consumidor, possibilitam a demonstração dos produtos, através da degustação, o que facilita a comercialização dos produtos. Segundo Brandão [51], a estratégia de venda no varejo pelo feirante pode ser aqui definida como venda no varejo independente, cuja importância é reconhecida na distribuição alimentar em pequenas cidades e periferias de grandes centros urbanos, porém, caracterizados por empreendimentos familiares de gestão pouco profissionalizada.

O grupo de feirantes com produção própria, durante a entrevista relata que reconhece a atividade de comercialização de queijo colonial não-legalizado como concorrência desleal, uma vez que os produtores legalizados precisam cumprir inúmeras exigências burocráticas e pagar as despesas impostas pelos órgãos fiscalizadores, para obter seu registro e seu selo de qualidade.

Os feirantes com produção terceirizada também têm uma produção em maior escala do que os demais produtores: compram leite de fornecedores e também participam de todos os processos de produção, armazenamento, embalagem e rotulagem. No entanto, devido à agroindústria ser legalizada e inspecionada por órgãos fiscalizadores de outro município, tem a possiblidade de comercializar seus produtos em mercados e padarias do município de origem, sendo este seu principal canal de comercialização. Entretanto, o feirante adotou as feiras do município de Santa Maria/RS por ser um canal de comercialização que admite a venda de produtos não-legalizados enquanto seu município de origem não adere ao Sistema Brasileiro de Inspeção de Produtos de Origem Animal - SISBI-POA ou ao Sistema Unificado Estadual de Sanidade Agroindustrial Familiar, Artesanal e de Pequeno Porte - SUSAF.

O feirante com venda de queijo oriundo de produção mista apresenta características distintas dos demais: tanto adquire queijo colonial de um grupo de produtores que permanecem em seus domicílios rurais quanto adquire em agroindústrias legalizadas e comercializa os produtos em feiras do Município, agregando mais valor. A opção por utilizar a feira deve-se ao fato de ser um local de venda direta ao consumidor, possibilidade de fortalecer as relações de confiança e possibilidade de despertar memória afetiva referente ao rural. Esta estratégia adotada pelo feirante pode estar fundamentada pela teoria de Custos de Transação, ou seja, o limite da racionalidade é afetado pela complexidade das transações. Segundo Williamson [52], a escolha das estratégias para diminuição dos custos envolvidos nas transações é influenciada pelo desempenho da racionalidade limitada e comportamento oportunista dos atores envolvidos que estão por sua vez ás propriedades ambientais como incerteza, frequência e especificidade dos agentes envolvidos.

Conforme o resultado da pesquisa, foram identificados três modelos por meio dos quais os feirantes operam a comercialização de queijo informal em Santa Maria/RS, o que corrobora com Brandão [51], que afirma que um novo padrão de flexibilidade produtiva, representado pela adaptabilidade das fronteiras organizacionais e busca por 
produtos inovadores pode ser denominado como novo modelo competitivo que é caracterizado pela busca por estratégias de aprimoramento contínuo de processos e produtos tal como a readequação mercadológica, viabilizada a partir de parcerias com fornecedores, consumidores e concorrentes, afetando diretamente a competitividade e os limites organizacionais vigentes.

As queijarias do município de Santa Maria/RS, assim como em toda região sul, estão caracterizadas em três segmentos, ou seja, das empresas que são fiscalizadas por órgãos oficias estaduais, os das empresas que são fiscalizadas pelo órgão de vigilância municipal e o das empresas que não passam por nenhum tipo de fiscalização. Não há registros oficiais da quantidade de queijo colonial comercializado no município, no entanto, é de conhecimento público a existência de inúmeras unidades de produção caseira e de agroindústrias produtoras não-legalizadas, o que corroborado pelos dados disponibilizados pelo GIPAG de que a maioria dos queijos coloniais comercializados em feiras santa-mariense são de origem artesanal.

O queijo tipo colonial, comumente produzido nas áreas rurais de Santa Maria/RS tem sido uma alternativa para pequenos produtores rurais incrementarem a renda familiar. A produção de alimentos na forma artesanal favorece a permanência das famílias no campo e além de geração de empregos, incentivando a valorização da cultura local, uma vez que comercializando os produtos coloniais, os produtores participam do fortalecimento da identidade sociocultural e gastronômica da sua região [53, 54]. Segundo Silva [55], além da importância social que a produção artesanal de queijos agrega às regiões produtoras, é evidenciada a sua importância histórica, cultural e econômica.

\section{Conclusões}

De acordo com pesquisa realizada constatou-se que há dez feiras no município de Santa Maria/RS, Brasil, com vinte e oito feirantes que comercializam queijo colonial, sendo que quatro feirantes realizam a venda de queijo oriundo de produção própria, vinte e três feirantes realizam a venda de queijo proveniente de produção terceirizada e um feirante efetua a comercialização de queijo derivado de produção mista.

De acordo com os dados coletados, a quantidade anual de queijo colonial comercializada no Município é de aproximadamente 46.760 kg/ano. No entanto, não há registros oficiais dessas quantidades comercializadas, mas é de conhecimento público a existência de inúmeras unidades de produção caseira e de agroindústrias produtoras não-legalizadas, o que corrobora para afirmar que a maioria dos queijos coloniais comercializados em feiras santa-mariense são de origem artesanal.

As questões acerca da legalização da produção e comercialização de queijo colonial são importantes do ponto de vista de saúde pública, no entanto é necessário atender as demandas que os agricultores familiares têm em relação a um modo de produção historicamente constituído. Deste modo, o desafio é encontrar um meio termo em que não se perca o que foi constituído, preservando o histórico cultural da região, ao mesmo tempo em que as condições sanitárias adequadas sejam respeitadas.

\section{Referências}

[1] Froelich P.R., Zanini M.C.C. Saberes e sabores da colônia: alimentação e cultura como abordagem para o estudo do rural [recurso eletrônico] / Menasche.R. org. Dados eletrônicos. - Porto Alegre: Editora da UFRGS, 2015. 344 p. Disponível em: $<$ https://www.ufrgs.br/gepac/arquivos/livros/saberes-e-sabores_livro.pdf>. Acesso em: 08. Ago. 2019. 
[2] Ide L.P.A., Benedet H.D. Contribuição ao conhecimento do queijo colonial produzido na região Serrana do estado de Santa Catarina, Brasil. Ciência Agrotecnologia 2001; 25(6):1351-1358.

[3] Costa V.S., Assunção A.B.A., Costa M.M.B., Chacon M.J.M. Análise de custos a partir da cadeia do valor do leite e seus derivados na região seridó do Rio Grande do Norte. Revista Ambiente Contábil 2015; 7(1):89-108. Disponível em: <https://periodicos.ufrn.br/ambiente/article/view/5602>. Acesso em 08. Abr. 2019.

[4] EMBRAPA. Anuário do Leite 2019. Edição Digital em embrapa.br/gado-de-leite Disponível em: <https://www.embrapa.br/gado-de-leite> Acesso em: 25 de Jul. 2019.

[5] Breitenbach R., Souza R.S. Estrutura, conduta e governança na cadeia produtiva do leite: um estudo multicaso no Rio Grande do Sul. Revista Eletrônica de Administração (Porto Alegre) REAd 2015; 82(3):750-78. https://doi.org/10.1590/14132311.0372014.53598.

[6] Canziani J.R. Cadeias Agroindustriais: O Programa Empreendedor Rural; Curitiba, SENAR-PR, 2003. p.21-22. Brasil.

[7] A International Farm Comparision Network. Relatório IFCN Dairy 2019 - Edição do $20^{\circ}$ aniversário. Disponível em:<https://ifcndairy.org/wp-content/uploads/2019/10/IFCNDairy-Report-Article-2019.pdf>. Acesso em 04 de Nov. 2019.

[8] EMBRAPA. Gado do Leite - Importância Econômica. Disponível em: < https://sistemasdeproducao.cnptia.embrapa.br/>. Acesso em 08. Ago. 2019.

[9] IBGE. Instituto Brasileiro de Geografia E Estatística. Levantamento Sistemático da Produção Agrícola. Rio de Janeiro, 2019. Disponível em: $<$ https://biblioteca.ibge.gov.br/index.php/biblioteca-catalogo?view=detalhes\&id=72415> Acesso em 05 de Jul. 2019.

[10] Batalha M. Gestão Agroindustrial: GEPAl: Grupo de Estudos e Pesquisas Agroindustriais. 3 ed. São Paulo: Atlas, 2012. 770p.

[11] Zylbersztajn D. Economia das Organizações. In: Zylbersztajn D, Neves M. F. org. Economia e Gestão dos Negócios Agroalimentares. São Paulo: Pioneira, 2000. 428p.

[12] Kotler P. Administração de marketing: Análise, Planejamento, Implementação e Controle. 5.ed. São Paulo: Atlas, 2011. 725 p.

[13] Cassol A., Schneider S. Produção e consumo de alimentos: novas redes e atores. Lua Nova 2015; 95:143-177. http://dx.doi.org/10.1590/0102-6445143-177/95.

[14] Brasil. Decreto $n^{\circ} 9.013$, de 29 de março de 2017. Regulamenta a Lei $n^{0} 1.283$, de 18 de dezembro de 1950, e a Lei no 7.889, de 23 de novembro de 1989, que dispõem sobre a inspeção industrial e sanitária de produtos de origem animal. Disponível em: https://www.gov.br/agricultura/pt-br/assuntos/inspecao/produtos-

animal/arquivos/decreto-n-9013-2017_alt-decreto-9069-2017_pt.pdf/view. Acesso em: 13 de Ago. de 2019.

[15] GAUCHAZH. Porto Alegre. Disponível em:

$<$ https://gauchazh.clicrbs.com.br/geral/noticia/2016/09/cerca-de-800-quilos-de-carne-eoutros-produtos-sao-apreendidos-em-julio-de-castilhos-7483967.html>Acesso em: 15 de Abr. 2019. G1. 
[16] Rio Grande do Sul 2. Secretária da Agricultura, Pecuária e Desenvolvimento Rural. Disponível em: <https://www.agricultura.rs.gov.br/regional-da-seapi-e-ida-desanta-maria-apreendem-produtos-de-origem-animal-em-acao-neste-sabado>. Acesso em: 15 de Abr. 2019.

[17] Rio Grande do Sul. Disponível em: <http://g1.globo.com/bom-diabrasil/noticia/2013/11/nova-fraude-no-leite-e-descoberta-no-rio-grande-do-sul.html> Acesso em: 15 de Abr. 2019.

[18] Ministério do Estado de Agricultura, Pecuária e Abastecimento. Departamento de Inspeção de Produtos de Origem Animal. Portaria no 146, de 07 de março de 1996. Aprova os Regulamentos Técnicos de Identidade e Qualidade dos Produtos Lácteos. Diário Oficial da República Federativa do Brasil, Brasília, 11 mar. 1996, Seção I, p. 3977.

[19] Agência Nacional de Vigilância Sanitária. Aprova o regulamento técnico sobre rotulagem nutricional de alimentos embalados. Resolução RDC $n^{\circ} 360$, de 23 de dezembro de 2003. Disponível em:

<http://portal.anvisa.gov.br/documents/33880/2568070/res0360_23_12_2003.pdf/5d4fc 713-9c66-4512-b3c1-afee57e7d9bc>. Acesso em: 05 abr. 2019.

[20] Vicentini N.M. Custo da adequação de pequenos produtores de queijos aos requisitos da legislação do estado de Minas Gerais. Revista do Instituto de Laticínios Cândido Tostes 2013; 68(395):5-14. https://doi.org/10.5935/2238-6416.20130043.

[21] Dorigon C, Renk A. Técnicas e métodos tradicionais de processamento de produtos coloniais: de "miudezas de colonos pobres" aos mercados de qualidade diferenciada. Rev. de Economia Agrícola 2011; 58(1):101-113. Disponível em: <http://www.iea.sp.gov.br/ftpiea/publicacoes/rea/2011/rea8-1-11.pdf> Acesso em: 19 de Ago. 2020.

[22] Mattiello C.A., Silveira S.M., Carli F., Cunha Junior A, Alessio D.R.M., Pelizza A., Cardozo L.L., Thaler Neto A. Rendimento industrial, eficiência de fabricação e características físico-químicas de queijo colonial produzido de leite com dois níveis de células somáticas. Arq. Bras. Med. Vet. Zootec. 2018; 70(6):1916-1924. https://doi.org/10.1590/1678-4162-9908.

[23] Brito L.M., Xavier A.F. Comportamento do Consumidor e o Mercado Informal de Produtos Artesanais. In: CLAV 2016. 2016. Disponível em: <http://bibliotecadigital.fgv.br/ocs/index.php/clav/clav2016/paper/view/5700/1620>. Acesso em: 04 de Nov. 2018.

[24] Mariot E.J. Produtos Agroalimentares Típicos (Coloniais): Situação e Perspectivas de Valorização no Município de Urussanga, Santa Catarina, Brasil. 2002. Dissertação (Mestrado Internacional em Gestão do Desenvolvimento Rural) - Universidade de Santiago da Compostela. Vila Real, Mar.2002. Disponível em: <file:///D:/Users/SAMSUNG/Downloads/Produtos\%20agroalimentares\%20t\%C3\%ADpi cos\%20coloniais\%20situa\%C3\%A7\%C3\%A30\%20e\%20perspectivas\%20de\%20valori za\%C3\%A7\%C3\%A3o\%20no\%20munic\%C3\%ADpio\%20de\%20Urussang\%20(1).pdf > Acesso em: 16 de Dez. 2018.

[25] Rezende P.H.L., Mendonça E.P., Melo R.T., Coelho L.R. Monteiro G.P., Rossi D.A. Aspectos sanitários do queijo minas artesanal comercializado em feiras livres. Revista do Instituto de Laticínios Cândido Tostes 2010; 65(377):36-42. https://doi.org/10.14295/2238-6416.v65i377.148. 
[26] Nhuch E., Guedes F.F., Vargas L., Koch F.F. Caracterização dos queijos artesanais produzidos em Viamão, no Estado do Rio Grande do Sul, quanto à evolução físicoquímica e microbiológica. Veterinária em foco 2004; 2(1):15-24. Disponível em: < http://www.ulbra.br/upload/fdef904d5f25b189416a7e1daeb559d8.pdf> Acesso em: 16 de Dez. 2018.

[27] Funck G.D., Hermanns G., Vicenzi R., Schmidt J.T., Richards N.S.P.S., Silva W.P., Fiorentini A.M. Microbiological and physicochemical characterization of the raw milk and the colonial type cheese from the Northwestern Frontier region of Rio Grande do Sul, Brasil. Revista do Instituto Adolfo Lutz 2015; 74(3):247-257.

[28] Nassu R.T., Araújo R. dos S., Borges M. de F., Lima J.R., Macedo B.A., Lima M. H.P., Bastos M. do S.R. Diagnóstico das condições de processamento de produtos regionais derivados do leite no Estado do Ceará. Boletim de pesquisa e desenvolvimento 1 Embrapa Agroindústria Tropical, v. 2, n.1, p.28. 2001. Disponível em: <http://www. cnpat.embrapa.br/publica/pub/BolPesq/p\%26d_1.pdf > Acesso em: 16 de Dez. 2018.

[29] Coletti V.D. Os agricultores familiares e a construção dos mercados do leite e queijo: a pequena produção e a qualidade frente à legislação brasileira e europeia. Dissertação de Mestrado. Programa de Pós-Graduação em Desenvolvimento regional. Universidade Tecnológica Federal do Paraná. Paraná, 2013. Disponível em: < http://repositorio.utfpr.edu.br/jspui/bitstream/1/701/1/PB_PPGDR_M_Coletti\%2C\%20Vi nicius\%20Deotan_2013.pdf>. Acesso em 08. Abr. 2019.

[30] Breitenbach R., Brandão J.B., Zorzan M. Vantagens e oportunismo no relacionamento entre associados e cooperativa de laticínios. Interações 2017; 18(2):45-58. https://doi.org/10.20435/inter.v18i2.1393.

[31] Leão L.H.C., Vasconcellos L.C.F. Nas trilhas das cadeias produtivas: reflexões sobre uma política integradora de vigilância em saúde, trabalho e ambiente. Revista Brasileira de Saúde Ocupacional 2013; 38(127):107-121. https://doi.org/10.1590/S0303-76572013000100013.

[32] Araújo M.J. Fundamentos do Agronegócio. 2nd ed. São Paulo: Atlas; 2007. 155p.

[33] Davis J.H., Goldberg R.A.A. Conceito de agronegócio. Boston: Divisão de Pesquisa, Escola de Graduação em Administração de Empresas, Universidade de Harvard; 1957. pp. 136.

[34] Pelinski A., Silva D.R., Shikida P.F.A. A dinâmica de uma pequena propriedade dentro de uma análise de filière. Organizações Rurais \& Agroindustriais 2005; 7(3):271-281.

[35] Zylbersztajn D. Estruturas de governança e coordenação do agribusiness: uma aplicação da nova economia das instituições. Tese de Livre Docência, Departamento de Administração. FEA/USP, 238 p., 1995.

[36] Kremer A.M., Talamini E. Análise da Social Netchain em cadeias do agronegócio: aplicação em uma cadeia brasileira de pescado. Interações (Campo Grande, MS) 2018; 19(3):457-470. https://doi.org/10.20435/inter.v0i0.1576.

[37] Fava L.W., Hernandes J.F.M., Pinto A.T., Scmidt V. Características de queijos artesanais tipo colonial comercializados em uma feira agropecuária. Acta Scientiae 
Veterinariae 2012; 40(4):1084. Disponível em: https://www.redalyc.org/pdf/2890/289023924019.pdf. Acesso em 03 Ago. 2020.

[38] Brasil. LEI N ${ }^{\circ}$ 9.933, de 20 de dezembro de 1999. Dispõe sobre as competências do Conmetro e do Inmetro, institui a Taxa de Serviços Metrológicos, e dá outras providências. Disponível em: <http://www.planalto.gov.br/ccivil_03/LEIS/L9933.htm> Acesso em 12. Abr. 2019.

[39] Zaffari C.B., Mello J.F., Costa M. Qualidade bacteriológica de queijos artesanais comercializados em estradas do litoral norte do Rio Grande do Sul, Brasil. Ciência Rural 2007; 37(3):862-867. http://dx.doi.org/10.1590/S0103-84782007000300040.

[40] Santos-Koell F.T., Mattana A., Hermes E. Avaliação microbiológica do queijo tipo mussarela e queijo colonial comercializado na região oeste do Paraná. Revista Brasileira de Tecnologia Agroindustrial 2009; 3(2):66-74. http://dx.doi.org/10.3895/S1981-36862009000200008.

[41] FIDA. Fundo Internacional de Desenvolvimento Agrícola. Principais canais de comercialização da agricultura familiar: Fundo Internacional de Desenvolvimento Agrícola (FIDA): IICA -Instituto Interamericano de Cooperação para Agricultura, 2018. Disponível em:

<http://www.mds.gov.br/webarquivos/arquivo/seguranca_alimentar/compra_institucion al/cartilha\%20Principais\%20Caniais\%20de\%20comercializa\%C3\%A7\%C3\%A3o\%20p ara\%20Agricultura\%20Familiar.pdf >. Acesso em 25 de Jul. 2019.

[42] Pozzebon L., Rambo A.G., Gazolla M. As Cadeias Curtas das Feiras Coloniais e Agroecológicas: Autoconsumo e Segurança Alimentar e Nutricional. Desenvolvimento em Questão 2018; 16(42):405-441. https://doi.org/10.21527/2237-6453.2018.42.405441.

[43] Goodman D. The quality 'turn' and alternative food practices: reflections and agenda. Journal of Rural Studies 2003; 19(1):1-7. http://dx.doi.org/10.1016/S07430167(02)00043-8.

[44] Cruz F.T., Schneider S. Qualidade dos alimentos, escalas de produção e valorização de produtos tradicionais. Revista Brasileira de Agroecologia Revista Brasileira de Agroecologia 2010; 5(2):22-38. ISSN: 1980-9735. Disponível em: <http://orgprints.org/24508/1/Cruz_Qualidade.pdf> Acesso em 08. Abr. 2019.

[45] G1. Rio Grande do Sul. Disponível em: <https://g1.globo.com/pr/parana/noticia/pfvai-as-ruas-para-cumprir-mandados-da-nova-fase-da-operacao-carne-fraca.ghtml> Acesso em: 15 de Abr. 2019.

[46] Avicultura Industrial. Disponível em: <https://www.aviculturaindustrial.com.br/imprensa/fraudes-em-alimentos-ameacam-aseguranca-alimentar/20171211-140000-b879>. Acesso em: 15 de Abr. 2019.

[47] Guerra J.F.C., Teodósio A.S.S. Pesquisa Qualitativa em Gestão Social: uma análise da produção de conhecimento em estudos de caso. Revista Gestão \& Tecnologia 2014; 14(3):160-176. https://doi.org/10.20397/2177-6652/2014.v14i3.444.

[48] Gil, A.C. Como elaborar projetos de pesquisa. 5 ed. São Paulo: Atlas. 2010. 176p.

[49] GIPAG. Caracterização das Feiras Livre de Santa Maria (RS). Destinatário: Valéria Bracinni. [S. I.], 10 dez. 2018. 1 mensagem eletrônica. 
[50] CNM. Confederação Nacional de Municípios. A Importância do Serviço de Inspeção Municipal (Sim) na Gestão Pública e para o Desenvolvimento Agroindustrial. -Brasília: CNM, 2015. Disponível em: $<$ https://www.cnm.org.br/cms/biblioteca_antiga/Servi\%C3\%A70\%20de\%20Inspe\%C3 $\% A 7 \%$ C3\%A30\%20Municipal\%20-\%20SIM\%20(2015).pdf>. Acesso em: 12 de Ago 2019.

[51] Brandão J.B. A gestão de cadeia de suprimentos das redes regionais do varejo de frutas, legumes e verduras no Rio Grande do Sul. Tese de Doutorado. Santa Maria: Universidade Federal de Santa Maria; 2011.

[52] Williamson O.E. Las instituciones económicas del capitalismo. México: Fondo de Cultura Económica, 1989. 436p.

[53] Machado E.C., Ferreira C.L., Fonseca L.M., Soares F.M., Pereira Júnior F.N. Características físico-químicas e sensoriais do queijo Minas artesanal produzido na região do Serro, Minas Gerais. Food Science and Technology 2004; 24(4):516-521. https://doi.org/10.1590/S0101-20612004000400006.

[54] Dorigon C. Le passage du modèle de l'agriculture familiale à un modèle coopératif familial autour des produits coloniaux au sud du Brésil. Bulletin de l'association de géographes français. Géographies 2015; 92(92-3):353-363. https://doi.org/10.4000/bagf.713.

[55] Silva J.G. Características físico-químicas e sensoriais do queijo Minas artesanal da Canastra. Dissertação de mestrado. Lavras: UFLA, 2007. Disponível em: <http://repositorio.ufla.br/bitstream/1/3064/1/DISSERTA\%C3\%87\%C3\%83O_Caracter \%C3\%ADsticas\%20f\%C3\%ADsicas\%2C\%20f\%C3\%ADsicoqu\%C3\%ADmicas\%20e\%20sensoriais\%20do\%20queijo\%20Minas\%20artesanal\%20d a\%20Canastra.pdf> > Acesso em: 16 de Dez. 2018.

\section{Autor}

Valéria Pinheiro Braccini ${ }^{1, \star}$, Regis Trentin Piovesan², Janaina Balk Brandão ${ }^{2}$, Neila Silvia Pereira dos Santos Richards ${ }^{1}$

1. Departamento de Tecnologia e Ciência dos Alimentos, Universidade Federal de Santa Maria - DTCA/UFSM, Avenida Roraíma, 1000, 97105-900, Santa Maria - RS, Brasil.

2. Departamento de Educação Agrícola e Extensão Rural, Universidade Federal de Santa Maria - DEAR/UFSM, Avenida Roraíma, 1000, 97105-900, Santa Maria - RS, Brasil.

* Autor para correspondência: valurug@gmail.com 